\title{
Plasma Immunoreactive Melanotrophic Hormones in Patients on Maintenance Haemodialysis
}

\author{
J. J. H. GILKES, \\ R. A. J. EADY, \\ LESLEY H. REES, \\ D. D. MUNRO, J. F. MOORHEAD
}

British Medical fournal, 1975, 1, 656-658

\begin{abstract}
Summary
Circulating levels of melanotrophic hormones and ACTH were determined in patients treated by maintenance dialysis for chronic renal failure. Plasma melanotrophic hormone levels were greatly increased in all patients studied (125-1100 $\mathrm{ng} / \mathrm{l}$ as compared with 12-36 $\mathrm{ng} / 1$ in normal adults) and were correlated with the duration of treatment. Skin pigmentation, especially in exposed areas, was notably increased, particularly in those patients with the highest plasma melanotrophic concentrations.

Plasma ACTH levels were normal or only slightly raised and circulating corticosteroid concentrations, as determined by a fluorimetric method, all lay within the physiological range. The dissociation between ACTH and melanotrophic hormone levels in these patients may have been the result of a slower metabolic clearance of the latter.
\end{abstract}

\section{Introduction}

The cause of skin pigmentation associated with renal failure is unknown. It has been attributed to the deposition of lipidsoluble pigments (lipochromes and carotenoids) in the epidermis and subcutaneous adipose tissue (Tsaltas, 1969), but the evidence is inconclusive. Recent studies by light and electron microscopy (R. A. J. Eady and J. J. H. Gilkes, unpublished observations) have confirmed a reported (Thiers et al., 1958) increase in melanin in clinically pigmented skin.

Increased circulating levels of ACTH and melanotrophic hormones have been found in disorders associated with definite pigmentation of the skin, notably Addison's disease and Nelson's syndrome (Abe et al., 1969). Initially it was thought that human $\beta$-melanocyte stimulating hormone $\left(\beta_{\mathrm{h}}-\mathrm{MSH}\right) *$ (Harris, 1959) caused this increased pigmentation. Recent evidence based on immunological, chromatographic, and stability studies (Scott and Lowry, 1974; Bloomfield and Scott, 1974; Bloomfield et al., 1974) suggests, however, that the hormones responsible are the larger $\beta$-lipotrophin $\left(\beta_{\mathrm{h}}-\mathrm{LPH}\right)(\mathrm{Li}$ et al., 1965; Cseh et al., 1972) and human $\gamma$-lipotrophin $\left(\gamma_{h}-\mathrm{LPH}\right)$, both of

*The nomenclature of $\mathrm{Li}(1959)$ is used.

Department of Chemical Pathology, St. Bartholomew's Hospital, London EC1A 7 BE

J. J. H. GILKES, M.B., M.R.C.P., Research Fellow (now Senior Registrar in Dermatology)

LESLEY H. REES, M.D., M.R.C.P., Lecturer

Department of Dermatology, St. Bartholomew's Hospital, London EC1A 7BE

D. D. MUNRO, M.B., F.R.C.P., Consultant Dermatologist

Institute of Dermatology, St. John's Hospital for Diseases of the Skin, London E9 6BX

R. A. J. EADY, M.B., M.R.C.P., Wellcome Trust Research Fellow

Department of Nephrology and Transplantation, Royal Free Hospital, London NW3 2X]

J. F. MOORHEAD, M.B., F.R.C.P., Director of Department which contain an identical sequence to $\beta_{\mathrm{h}}-\mathrm{MSH}$ within their structures. Until this controversy is resolved we shall apply the general term melanotrophic hormone(s). Abe et al. (1969) showed that circulating levels of ACTH and the melanotrophic hormone closely parallel each other in a variety of clinical conditions, which suggested that both were controlled by the same mechanism.

We measured plasma levels of immunoreactive melanotrophic hormones in patients with chronic renal failure treated by maintenance dialysis to determine the hormones' possible role in the abnormal pigmentation often found in this group. In doing so we also discovered a dissociation between the circulating levels of ACTH and those of the melanotrophic hormones.

\section{Patients and Methods}

Twenty-four patients (14 men and 10 women, aged 17-54 years) from the renal unit, Royal Free Hospital, London, gave informed consent for their inclusion in the study. Twenty-two patients had been treated by haemodialysis for periods of from three months to 11 years using flat-plate dialysers (Kiil; Gambro) and warm singlepass dialysate supply systems (24-30 hours per week) (Moorhead et al., 1969). The remaining two patients nad started intermittent peritoneal dialysis (100-120 litres of dialysate per week) three weeks previously. The cause of renal failure was glomerulonephritis in all but six patients, and all had glomerular filtration rates of less than $1 \mathrm{ml} / \mathrm{min}$.

In 17 patients blood samples were taken before dialysis and after a 15-minute rest period, and in the remaining seven they were taken two hours after the start of dialysis. Two patients had samples taken both immediately before and after haemodialysis. Except on three occasions when they were collected at 9 p.m. samples were collected between 9 a.m. and 10.30 a.m. using plastic syringes containing heparin. They were then centrifuged, separated within 10 minutes, and plasma-frozen immediately in dry ice and stored at $-20^{\circ} \mathrm{C}$ until assayed. Plasma for corticosteroid estimations was kept at $4^{\circ} \mathrm{C}$.

Radioimmunoassays using an extraction procedure with Vycor glass (Corning Glass Works, New York) were used to measure plasma ACTH (20 patients) and melanotrophic hormone (24 patients). The ACTH assay has been described by Rees et al. (1971) and the specificity of the N-terminal antisera by Orth (1974). The melanotrophic hormone $\left(\beta_{h}-\mathrm{MSH}\right)$ assay used synthetic $\beta_{h}-\mathrm{MSH}$ for iodination and standardization, and the antisera cross-reacted fully with synthetic $\beta_{h}-M S H$ and natural $\beta_{h}-$ and $\gamma_{h}-L P H$ (Gilkes et al., 1975). Both determinations were done simultaneously on the same sample. Plasma corticosteroids ( 24 patients) were measured by a fluorimetric technique (Mattingly, 1962).

Skin Pigmentation.-The patients were asked if they thought their skin had changed in colour since starting on dialysis, and the degree of skin pigmentation was assessed clinically by two independent observers. Reflectance meters were not used.

\section{Results}

Plasma Melanotrophic Hormone.-Greatly raised plasma concentrations (125-1100 ng/l) well above our normal range (12-36 ng/l; Gilkes et al., 1975) were found in all patients (fig. 1). The highest levels were in patients who had been on haemodialysis for the longest periods, and plasma concentration and duration of treatment correlated well $(r=0.85 ; P<0.001 ;$ fig. 2$)$. In the two patients studied before and after haemodialysis there was no significant difference in the plasma concentrations. The two patients on peritoneal dialysis had plasma levels of 280 and $475 \mathrm{ng} / 1$. 


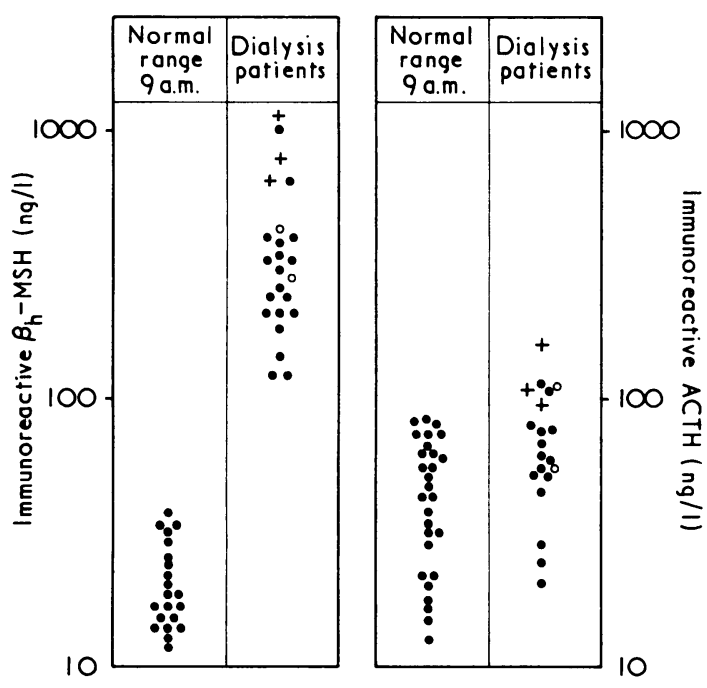

FIG. 1.-Plasma concentrations of immunoreactive $\beta_{h}-\mathrm{MSH}$ (melanotrophic hormone) and ACTH drawn on log scale in patients on dialysis compared to normal range at 9 a.m. $+=9.0$ p.m. samples. $O=$ Peritoneal dialysis patients.

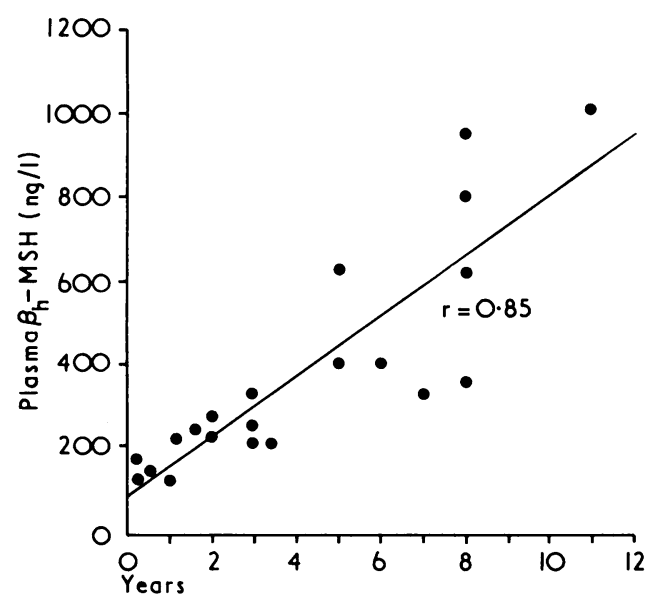

FIG. 2-Correlation between plasma $\beta \mathrm{h}-\mathrm{MSH}$ (melanotrophic hormone) and number of years on dialysis.

Plasma ACTH and Corticosteroids.-Fourteen patients had plasma ACTH concentrations within our norml range (15-85 ng/l) but six had slightly raised levels (93-165 ng/1). Though ACTH and melanotrophic hormone levels correlated well $(r=0.80 ; P<0.001)$ the concentrations of ACTH were up to 20 times lower on a molar equivalent basis. Plasma fluorogenic corticosteroid levels were within the physiological range $(6-26 \mathrm{mg} / \mathrm{l})$.

Skin pigmentation was greatest in the four patients with the highest plasma concentrations of melanotrophic hormone, one of whom had vitiligo as well as hyperpigmentation. Two patients who had been treated by haemodialysis for over five years and had plasma levels above $350 \mathrm{ng} / \mathrm{l}$, however, had pale sallow complexions. Three patients with concentrations below $250 \mathrm{ng} / 1$ had not noticed any change in skin colour, though another, with a value of $185 \mathrm{ng} / 1$, was strikingly pigmented. Two patients with levels of 399 and $144 \mathrm{ng} / 1$ felt that their skin had become paler since starting haemodialysis. The pigmentation in those patients affected was largely limited to the sun-exposed areas. Several said that their skin tanned readily and that the tan would persist apparently unchanged or with little fading for up to a year.

\section{Discussion}

The raised plasma concentrations of immunoreactive melanotrophic hormone found in patients being treated with dialysis are within the same range as those found in Addison's disease and Nelson's syndrome-both conditions associated with abnormal pigmentation. In other pathological and physiological conditions - for example, stress-in which raised plasma concentrations have been found there has been at least an equal increase in plasma ACTH (Abe et al., 1969; Donald and Toth, 1973). All our patients had greatly raised immunoreactive melanotrophic activity without an equivalent increase in ACTH levels, and plasma fluorogenic corticosteroids were also all within the physiological range.

The dissociation between the circulating levels of the two pituitary peptides is difficult to explain. In-vitro studies have shown that endogenous melanotrophic hormone (Gilkes et al., 1974) is more resistant to enzymatic breakdown than ACTH (Besser et al., 1971) in fresh blood or plasma. This difference may be accentuated in patients on dialysis as values before and after dialysis were similar, indicating that haemodialysis does not seem to remove significant amounts of these peptides. The extra-renal metabolic clearance of the larger peptides $\left(\beta_{h}-\right.$ and $\left.\gamma_{h}-\mathrm{LPH}\right)$ which are thought to constitute the immunoreactive melanotrophic hormone could be slower than that of the smaller molecule ACTH.

The progressive increase in the plasma melanotrophic hormone concentrations with length of treatment is also difficult to explain. Two patients on peritoneal dialysis had higher plasma concentrations than those who had recently started haemodialysis, and the paling of the skin noted by two other patients could be explained by an initial fall in plasma levels after starting treatment. We do not know whether patients with chronic renal failure have raised plasma levels of melanotrophic hormone before starting dialysis or whether these levels return to normal after transplantation. We intend to investigate further.

The slightly raised plasma immunoreactive ACTH concentrations in some of our patients is of interest because others (Varghese et al., 1969; Asbach et al., 1974) have shown a lack of the normal nyctohemeral rhythm of corticosteroids in dialysis patients. Such patients, however, do not develop the overt clinical features associated with Cushing's syndrome.

Our findings suggest that the abnormal pigmentation seen in patients on maintenance dialysis may be due to raised circulating levels of melanotrophic hormone. To have determined whether the immunoreactive hormone also had biological activity would have required large volumes of blood and would have been unethical as most patients were already anaemic.

We thank Dr. Z. Varghese and the nursing and technical staff of the renal unit, Royal Free Hospital, for their help in collection of blood samples; Mrs. A. Robinson for plasma-corticosteroid determinations; and Professor J. Landon for his help and interest.

\section{References}

Abe, K., et al. (1969). Fournal of Clinical Investigation, 48, 1580.

Asbach, H. W., Schuler, H. W., and Vecsei, P. (1974). New England fournal of Medicine, 291, 422

Besser, G. M., et al. (1971). fournal of Clinical Endocrinology and Metabolism, 32, 595 .

Bloomfield, G. A., and Scott, A. P. (1974). Proceedings of the Royal Society of Medicine, 67, 748 .

Bloomfield, G. A., et al. (1974). Nature, 252, 492.

Cseh, G., et al. (1972). Federation of European Biochemical Society, Letters, $21,344$.

Donald, R. A., and Toth, A. (1973). Fournal of Clinical Endocrinology and Metabolism, 36, 925 .

Gilkes, J. J. H., et al. (1974). Proceedings of the Royal Society of Medicine, $67,876$.

Gilkes, J. J. H., et al. (1975). Fournal of Clinical Endocrinology and Metabolism, 40,448 .

Harris, J. I. (1959). Nature, 184, 167.

Li, C. H. (1959). Science, 129, 969.

Li, C. H., et al. (1965). Nature, 208, 1093.

Mattingly, D. (1962). Fournal of Clinical Pathology, 15, 374.

Moorhead, J. F., Baillod, R. A., and Hopewell, J. P. (1969). Proceedings of the 4th International Congress of Nephrology, Stockholm, 3,131.

Orth, D. N. (1974). Methods of Hormone Radioimmunoassay, ed. B. M. Jaffe and H. R. Behrman, p. 125. New York, Academic Press.

Rees, L. H. . et al. (1971). Endocrinology, 89, 254.

Rees, L. H., et al. (1971). Endocrinology, 89, 254 .

Thiers, H., et al. (1958). Annales de Dermatologie et de Syphiligraphie, 85, 267

Tsaltas, T. T. (1969). Transactions. American Society for Artificial Internal

Organs, 15, 321. (1969). Annals of Clinical Biochemistry, 6, 157.
Varghese, Z., et al. 